\title{
A Bibliometric Analysis of the Most-Cited Articles on Craniospinal Epidural Hematoma
}

\author{
Sarah BIN ABDULQADER ${ }^{1}$, Othman T. ALMUTAIRI ${ }^{1}$, Modhi A. ALHUSSINAN², Turki ELARJANI ${ }^{3}$, \\ Abdullah ALBATHI ${ }^{4}$, Abdulrahman Y. ALTURKI ${ }^{1,5}$, Mohammed BAFAQUH ${ }^{1}$ \\ ${ }^{1}$ National Neuroscience Institute King Fahad Medical City, Department of Neurosurgery, Riyadh, Kingdom of Saudi Arabia \\ ${ }^{2}$ Alfaisal University, College of Medicine, Riyadh, Kingdom of Saudi Arabia. \\ ${ }^{3}$ University of Miami, Department of Neurological Surgery, Miami, Florida, United States of America. \\ ${ }^{4}$ College of Medicine, King Abdulaziz University Hospital, Jeddah, Kingdom of Saudi Arabia. \\ ${ }^{5}$ Division of Neurocritical Care, Critical Care Administration, King Fahad Medical City, Riyadh, Saudi Arabia
}

Corresponding author: Sarah BIN ABDULQADER binabdulqader@gmail.com

\section{ABSTRACT}

AIM: Epidural hematoma $(E D H)$ is a commonly encountered neurosurgical condition. Numerous articles have been published on $\mathrm{EDH}$. Bibliometric analysis studies the chronological trends and ranks the most impactful articles in a given field. The aim of this paper is to analyze the most-cited articles on cranial and spinal EDH.

MATERIAL and METHODS: A title-specific search was performed on the Scopus database using the term "epidural hematoma" in June 2020, with no publication date restrictions. The top 100 most-cited articles were collected, reviewed, and analyzed.

RESULTS: A total of 2165 articles were published on EDH from 1949 to 2020, and the top 100 most-cited ones were published between 1966 and 2014, receiving an average citation of 84.7 per paper. Most papers were published in Neurosurgery and Journal of Neurosurgery (JNS). $48 \%$ of the most-cited articles on EDH originated from the United States of America (USA). Notably, studies on spinal EDH represented $75 \%$ of the most-cited articles in our review. The most-cited article on EDH was published by Lawton et al. in 1995, receiving a total of 412 citations at an annual citation rate of $16.4 \%$.

CONCLUSION: This report identifies the most influential publications on EDH as well as the publications trends over the last 70 years. Recognition of the most impactful work is an important tool for clinicians and researchers as it can reflect the enormous changes in the clinical practice. This report can serve as a guide for developing evidence-based practices and identifying areas of research inadequacy.

KEYWORDS: Epidural hematoma, Spinal epidural hematoma, Bibliometric, Citation analysis

ABBREVIATIONS: H-Index: Hirsch index, SNIP: Journal's Source Normalized Impact Per Paper, SJR: Journal's SCImago Journal Rank, IF: Journal impact factor, CC: Citation count, CY: Citation per year, EDH: Epidural hematoma

\section{INTRODUCTION}

$\mathrm{E}$ pidural hematoma $(E D H)$ is a commonly encountered neurosurgical condition. EDH can be classified as cranial or spinal based on its location and as traumatic or non-traumatic based on etiopathological factors (infection/abscess, coagulopathy, hemorrhagic tumors, and vascular malformation). Cranial EDH, which is mostly attributed to traumatic brain injury, represents $2-10 \%$ of all types of head injuries and has a mortality rate of $1.2-33 \%$ $(6,7,9,13,16,22,32)$. In most cases, the source of bleeding
Sarah BIN ABDULQADER (1) : 0000-0002-7769-3891 Othman T. ALMUTAIRI

Modhi A. ALHUSSINAN
(D) : 0000-0001-9438-1542

(1) : $0000-0001-9446-7653$
Turki ELARJANI

Abdullah ALBATHI

Abdulrahman Y. ALTURKI
(1) : 0000-0001-9583-6123

(D) : 0000-0001-8930-0621

(D) : $0000-0002-1689-9247$
Mohammed BAFAQUH (1) : 0000-0002-3829-4837 
is an arterial branch of the middle meningeal artery, which underlies the pterion (18). Spinal EDH, on the other hand, has diverse causes and risk factors, including trauma, vascular malformation, coagulopathies, and the use of anticoagulant medications. Focal neurological deficits resulting from spinal cord compression are the most common signs or symptoms of spinal EDH (19). Cranial EDH management primarily aims to decrease intracranial pressure (ICP) and improve mass effectrelated symptoms (5). The management of spinal EDH involves decompressing the spinal cord, limiting further progression, and preserving function (19).

Citation analysis remains one of the most widely recognized methods of quantifying the impact of articles and the contribution of authors, journals, and institutions to a particular field (26). In addition, it studies the chronological trends of the articles, culminating at the most contemporary category. Bibliometric analyses have been applied to various subjects in many different medical specialties, including neurosurgery $(1,2,27,21,3)$, neurology $(15,23,29)$, psychiatry $(25)$, radiology (17), urology (28), and orthopedics (20).

$\mathrm{EDH}$ has been a subject of extensive research for several years, with articles published in the late 19th century covering almost every aspect of the disease, including incidence and epidemiology, management, diagnosis, and treatment costs. The objective of the present study was to conduct a bibliometric analysis of the top 100 most-cited articles on $\mathrm{EDH}$. Bibliometric trends analysis acts as an important source for highlighting impactful studies that have contributed to evidence-based clinical practice.

\section{MATERIAL and METHODS}

The execution of this bibliometric analysis involved a specific, keyword-based database search using Scopus as the search engine and without placing restrictions on the publication dates. To identify the most-cited articles, "Epidural Hematoma" was used as the keyword. The identified articles were stratified based on their respective citation counts, and the top 100 most-cited articles were obtained and categorized based on a thorough review. The identified categories were as follows: clinical, diagnosis, epidemiology, etiology, management, pathophysiology, and prognosis. Further clustering of data stratified the most-cited articles, based on the location of the $\mathrm{EDH}$, as spinal or cranial. The following important articlebased parameters were collected for analytical correlation: the article's citation count, article's citation per year, article's year of publication, contributing authors, specialty of the top contributing authors, most contributing author's H-Index, affiliation of the corresponding authors, country of publication, journal of publication, journal's impact factor, journal's source normalized impact per paper (SNIP), and journal's SCImago journal rank (SJR).

\section{RESULTS}

This bibliometrics-based search identified a total of 2165 articles published on EDH from 1949 to June 2020. The top 100 most-cited articles were published between 1966 and 2014 and had an accumulative citation count of 8447 , with 84.7 as the average number of citations per paper and $1.19 \%$ as the rate of self-citation for all the authors (Table I, Figure 1). Studies assessing spinal EDH comprised two-thirds of the most-cited articles (Figure 2), and clinical studies accounted for one-third of the list (Figure 3). The United States of America (USA) contributed to approximately half of the most-cited articles (Figure 4). The University of Ghang Gung Memorial Hospital, Taiwan, was the most active in studying EDH, having published eight of the 100 articles (Figure 5). Neurosurgery and the Journal of Neurosurgery were the top two highest contributing journals in the list, with 17 and 14 articles, respectively (Figure 6). An analysis of the contributing authors revealed similar contributions among those who contributed two or more articles (Figure 7). The list of the top 20 authors showed that neurosurgeons contributed the most to the list.

The most-cited article on EDH, entitled "Surgical management of spinal epidural hematoma: Relationship between surgical



Figure 1: Publications trends related to $\mathrm{EDH}$. 


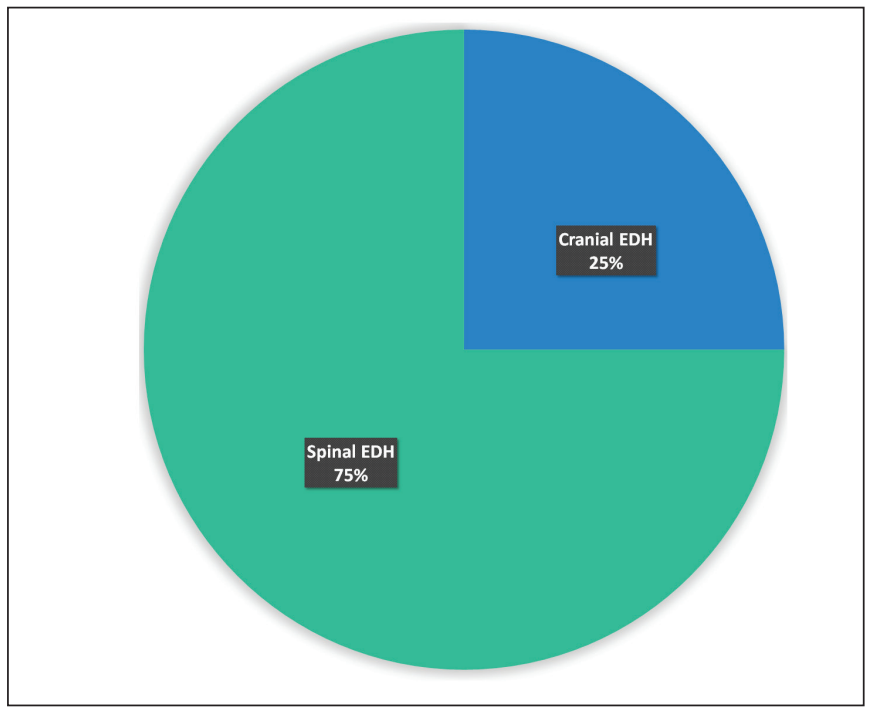

Figure 2: Studies on cranial versus spinal EDH.

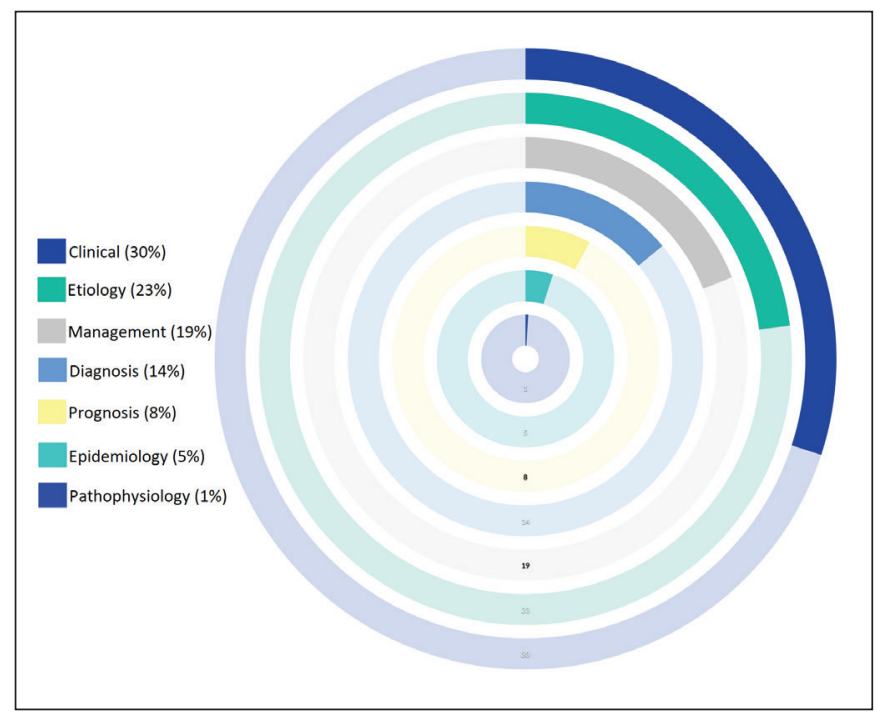

Figure 3: Study categories.

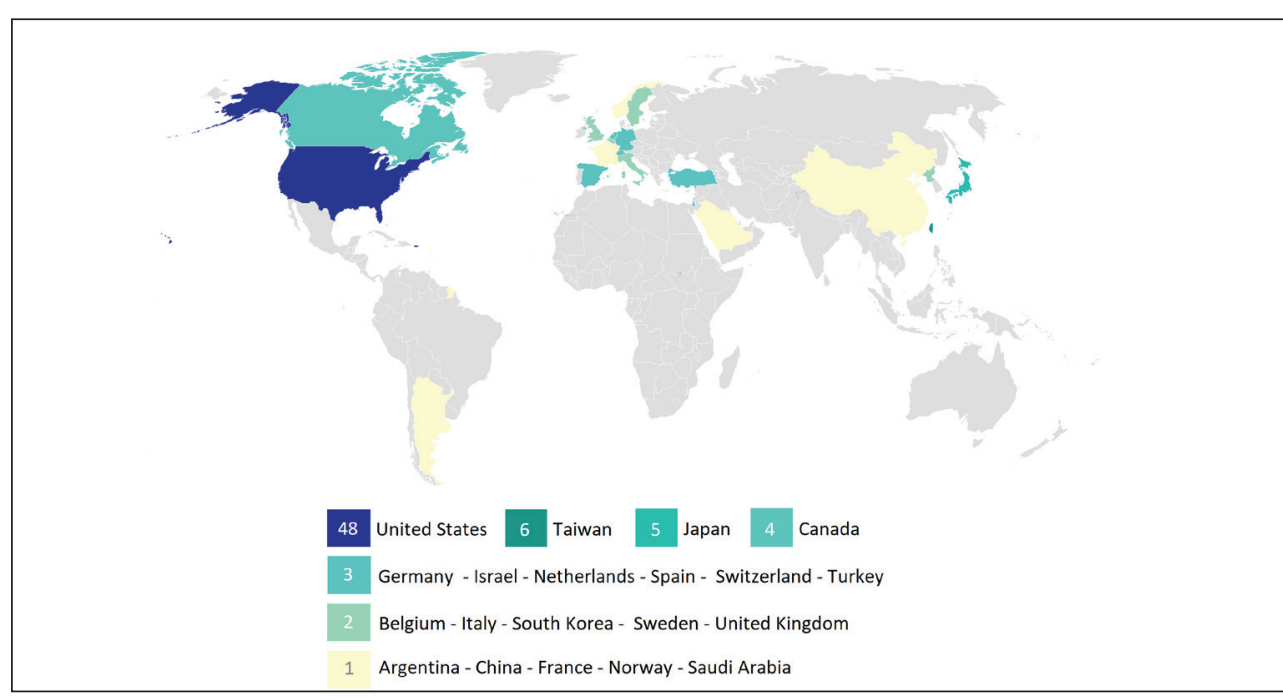

Figure 4: Countries contributing to EDH research.

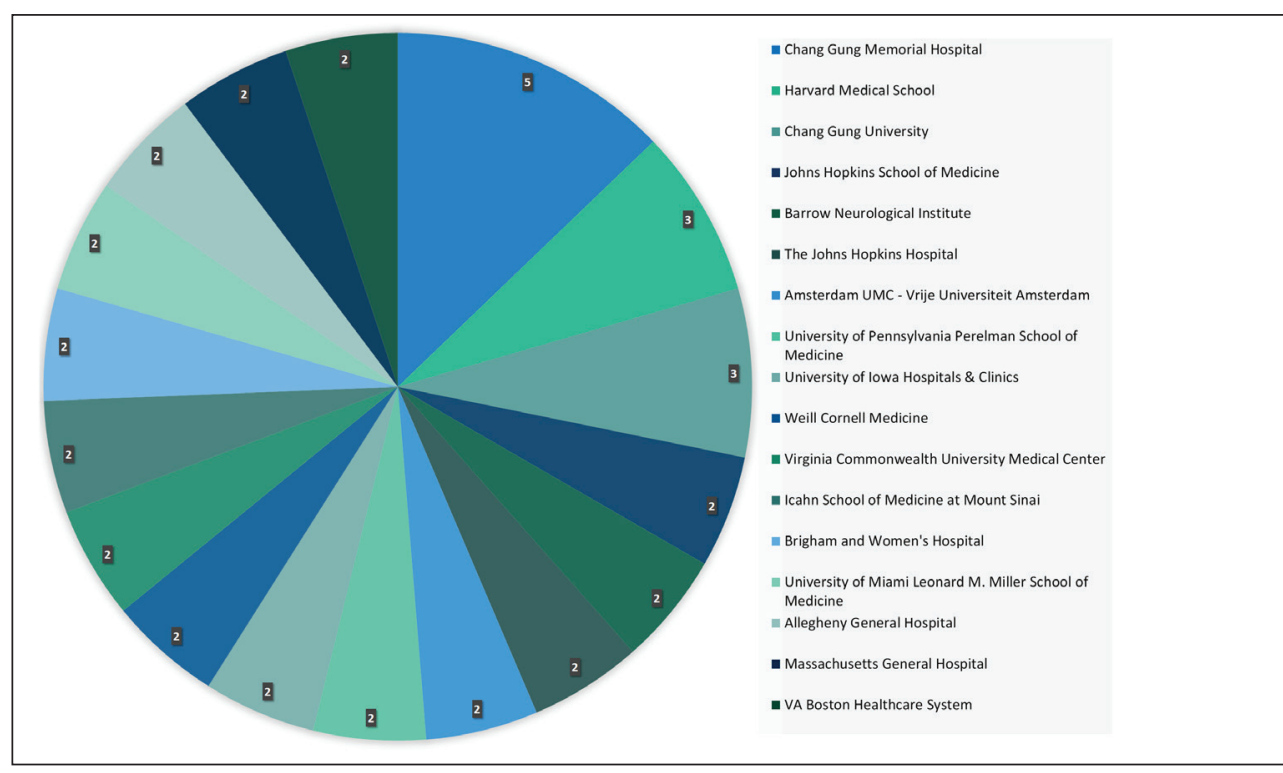

Figure 5: Institutions contributing to EDH research. 


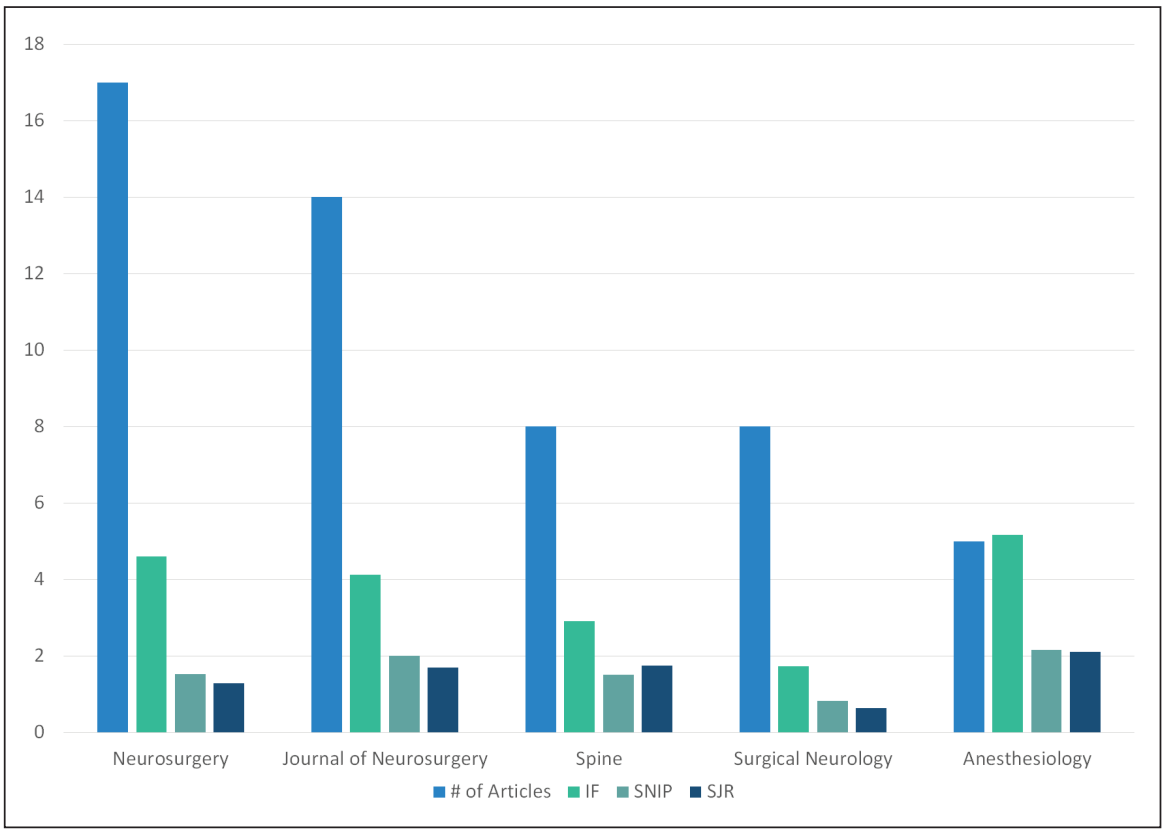

Figure 6: Journals contributing to EDH research.

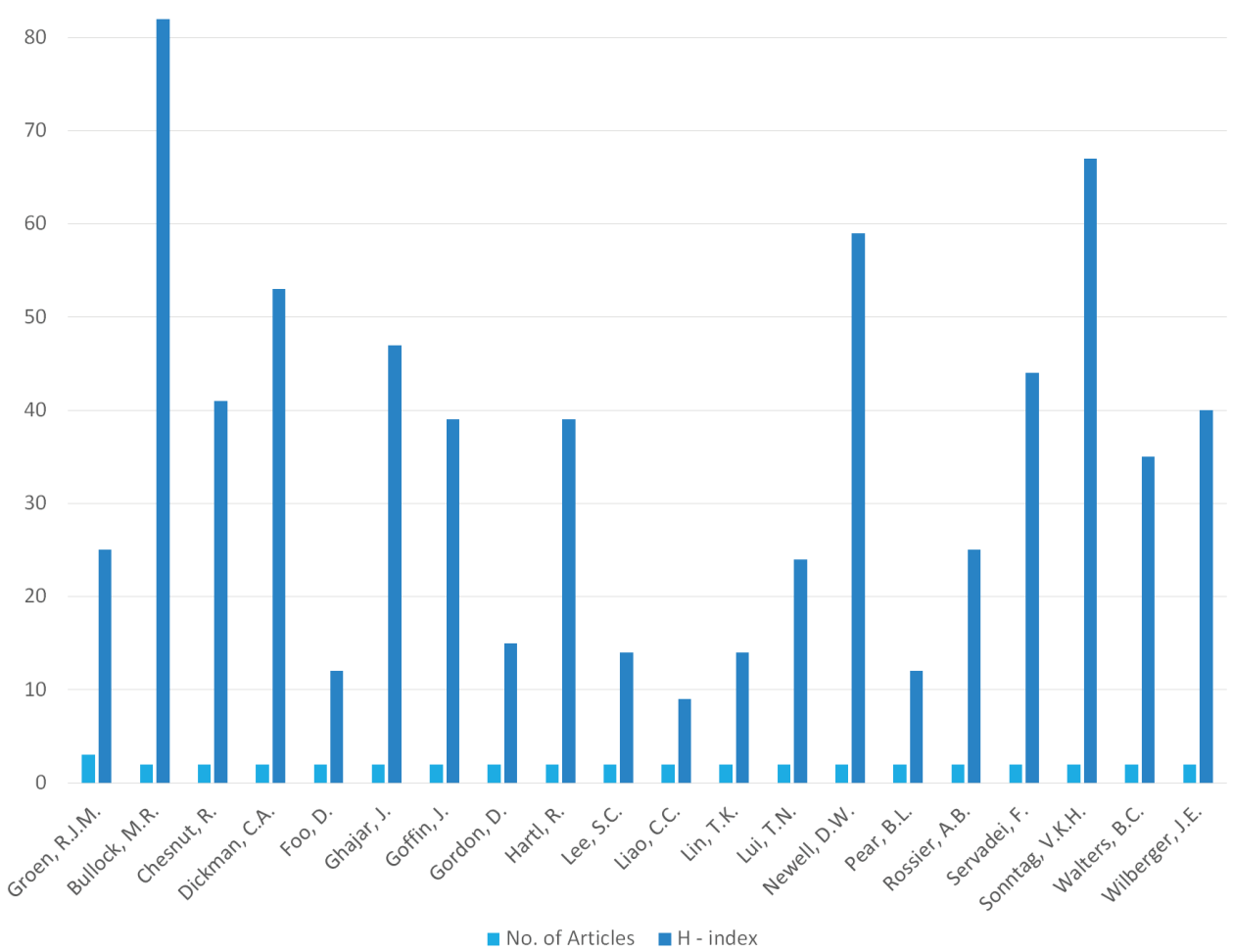

Figure 7: Authors contributing to EDH research. 


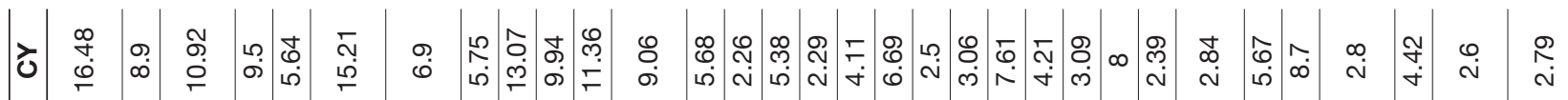
○

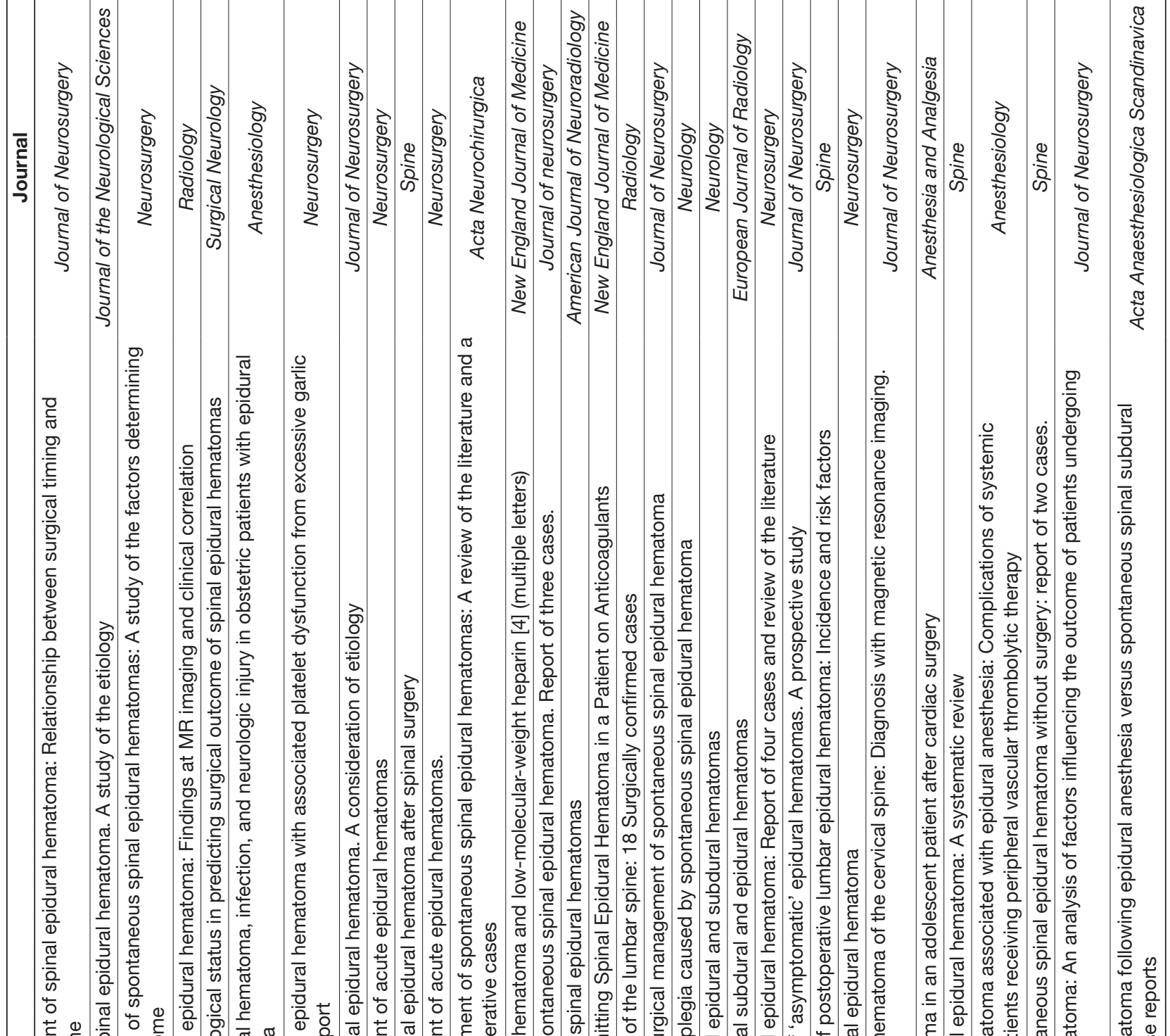

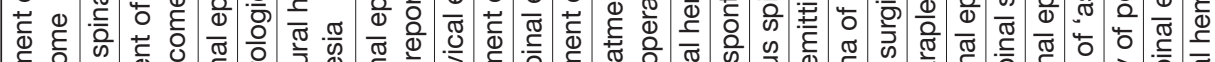




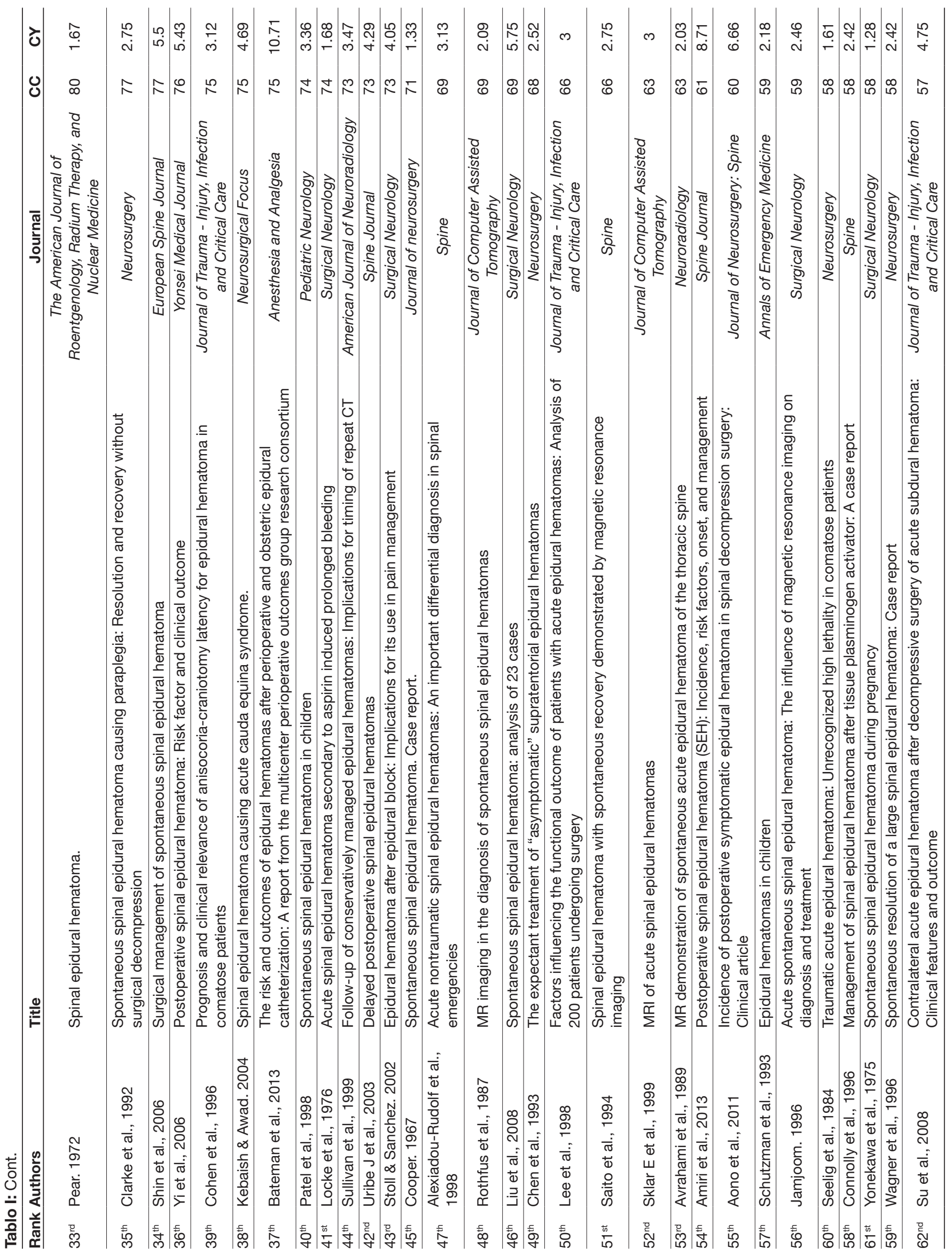




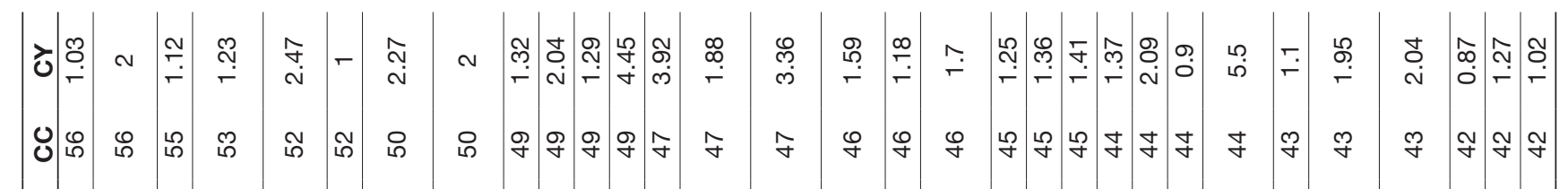

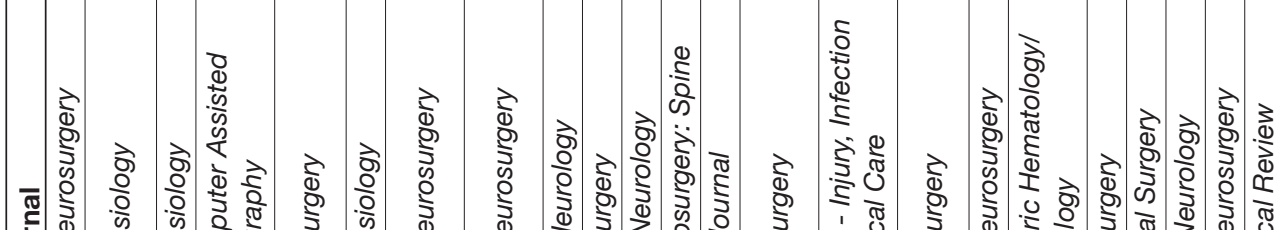

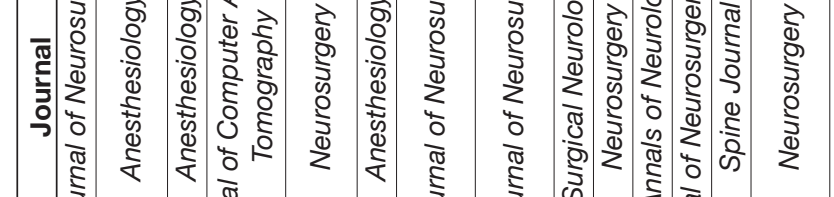

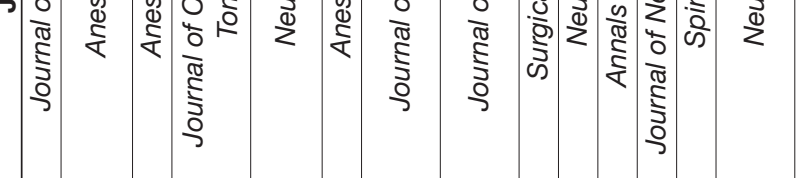

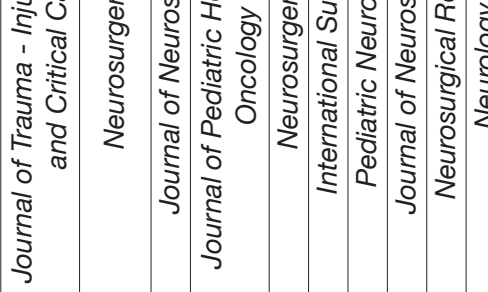
(2)

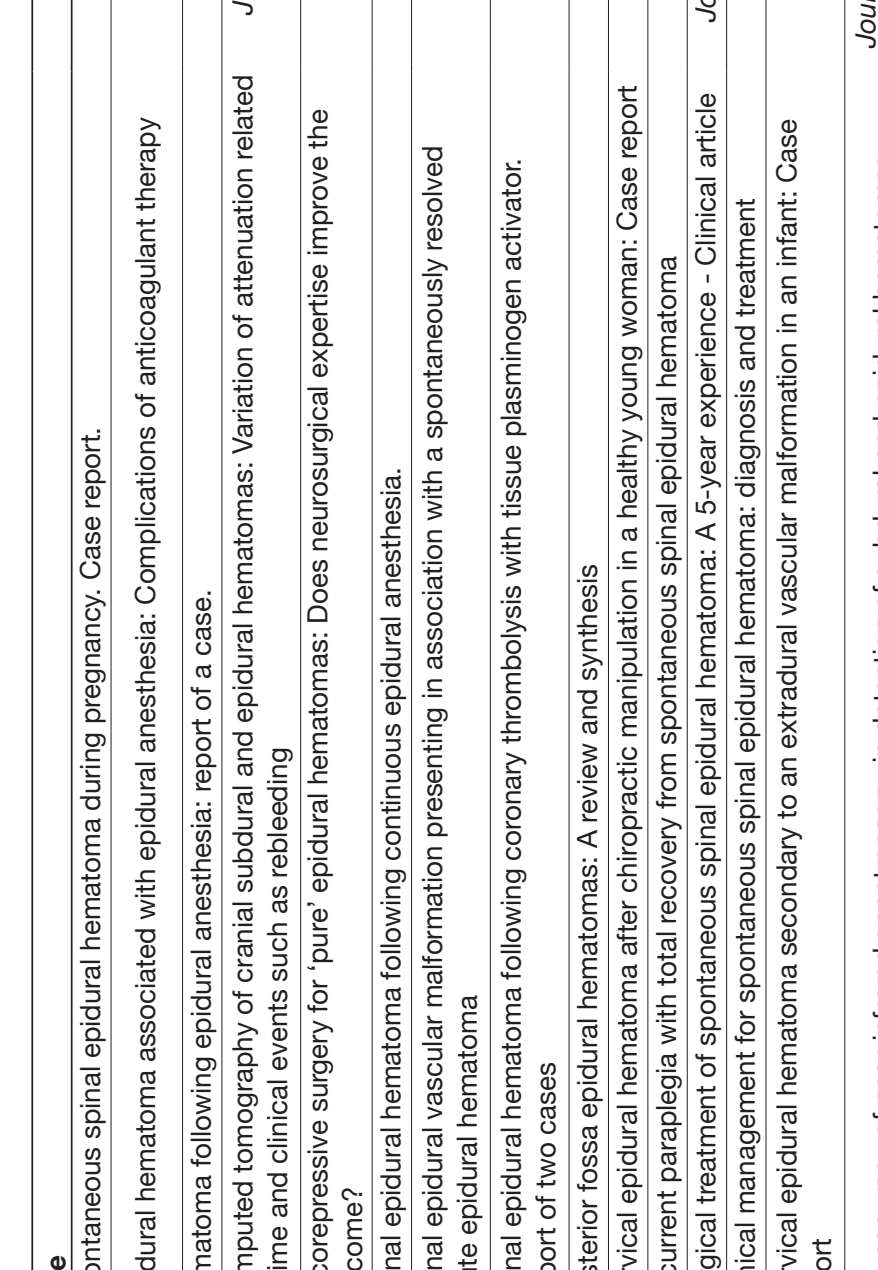

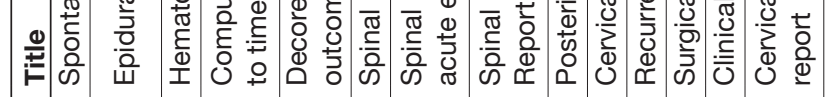




timing and neurological outcome," was written by Lawton M. T. et al. and published in the Journal of Neurosurgery in 1995. It collected 412 citations since its publication at a rate of $16.4 \%$ citations per year.

\section{DISCUSSION}

The significance of bibliometric studies is not necessarily evaluating the quality of research or its impact on clinical practice. Instead, they can provide a historical overview of the research conducted in a given field and reflect enormous changes in clinical practice over the years. In the first two decades (1966-1974) and (1975-1984), the literature on EDH focused prominently on spinal EDH. Most of the published papers were case reports describing cases of spontaneous spinal EDH as well as instances of spinal EDH following epidural anesthesia or the use of anticoagulant or antiplatelet medications. Notably, as computed tomography (CT) was introduced to the medical field after 1970, the correlation between the impact time of trauma and the radiological appearance of EDH on CT scans became the main area of interest. However, the management of EDH was not thoroughly studied at the time. Three articles focusing on the management of spontaneous as well as traumatic spinal EDH were published, with diverse opinions on surgical versus conservative management.

In the following decade (1985-1994), studies on the management of EDH started to flourish. Non-operative treatment options were discussed for both traumatic and nontraumatic cases of spinal and cranial EDHs. The introduction of magnetic resonance imaging (MRI) in the 1980s had a significant clinical impact on the management of EDH. The clinical significance of MRI in the diagnosis and follow-up of spinal EDH was a subject of interest during this decade. Later on, MRI served as the most accurate diagnostic tool for spinal $\mathrm{EDH}$, replacing the former practice of using CT scans and myelography. Articles on spinal EDH after the administration of epidural anesthesia continued to be produced during this decade, with all articles sharing the same evidence level as those in the previous two decades.

The peak of publications in our review was found to be between 1995 and 2004. In the 1990s, a significant number of clinical trials were published on the effectiveness of lowmolecular-weight heparin (enoxaparin) as both preventive and therapeutic treatment options for various thromboembolic events. Similarly, the utility of tissue plasminogen activator (tPA) in the treatment of ischemic stroke was also a subject of multiple clinical trials in the same era. Both of these contributed to the literature on spinal EDHs, with six articles being produced on the same subject. Other subjects addressed during this decade included the timing for repeating CT scans in patients treated conservatively, the utility of angiographic studies in the diagnosis of spontaneous spinal EDH, and operative options and their outcomes.

Starting from 2004, studies with higher levels of evidence were published, focusing mainly on incidence, risk factors, management, outcomes, and predictors of good recovery. 
The highest evidence-level in our list were systematic review and meta-analysis while clinical trials were not included.

\section{Spinal EDH}

Spinal EDH was extensively discussed in the literature, comprising two-thirds of the articles on our list. Diverse categories were studied, including the incidence, diagnosis, etiology, management, and outcomes of the disease. However, studies on cranial EDHs were not as popular. Spinal $\mathrm{EDH}$ was considered an emerging clinical entity having various etiologies and treatment options, and MRIs were frequently performed. The difficulty in its evaluation prior to the MRI era could explain why spinal EDH received more attention upon the introduction of MRI.

The most-cited article on Spinal EDH, which ranked 1st overall, is "Surgical management of spinal epidural hematoma: Relationship between surgical timing and neurological outcome" by Lawton et al., published in the Journal of Neurosurgery in 1995. It gained 412 CC and $16.48 \mathrm{CY}$. In this article, the surgical management of spinal EDH was discussed in depth, demonstrating how diagnosing and managing this disease with efficient timing maximize neurological recovery (18). The second most cited article on spinal EDH is Groen and Ponssen's "The spontaneous spinal epidural hematoma. A study of etiology," which also ranked $2^{\text {nd }}$ overall. This paper was published in the Journal of the Neurological Sciences in 1990 and received $267 \mathrm{CC}$ and $8.9 \mathrm{CY}$. As vascular anomalies were discussed since the 1960s as a possible cause of spontaneous spinal EDH, Groen and Ponssen concluded that most cases resulted from a ruptured vertebral venous plexus and that a cluster-type artery can be mistakenly considered a vascular anomaly (11).

\section{Cranial EDH}

Cranial EDHs were the subject of 25 articles in our list. Early articles focused on the recognition of EDH on CT scan and then shifted towards discussing management options and predictors of poor prognosis. The most-cited article on cranial $\mathrm{EDH}$, which ranked $9^{\text {th }}$ overall, is "Surgical management of acute epidural hematomas" by Bullock et al., published in 2006 in Neurosurgery as part of the guidelines for the surgical management of traumatic brain injury. This paper received $183 \mathrm{CC}$ and $13.07 \mathrm{CY}$ and is considered a landmark paper in the management of traumatic brain injury; it provides the indications, timing, and operative options for traumatic $\mathrm{EDH}$ that are currently implemented in clinical practice. The surgical indications include an EDH with a volume of $30 \mathrm{~cm}^{3}$ or more, regardless of the patient's GCS, with craniotomy for hematoma evacuation being performed as soon as possible, specifically when a patient has a GCS below 9 and unequal pupils. The authors also concluded that an $\mathrm{EDH}$ with a volume less than $30 \mathrm{~cm}^{3}$, thickness less than $15 \mathrm{~mm}$, and a midline shift less than a $5 \mathrm{~mm}$ in patients with a GCS more than 8 can be managed conservatively with serial CT scanning and close neurological monitoring (19). A noteworthy article on the cranial entity is "Acute epidural hematoma: an analysis of factors influencing the outcome of patients undergoing surgery in coma" by Lobato et al., published in the Journal of Neurosurgery in 1988. The authors studied the impact of surgical timing on the outcomes, concluding that patients who were operated on early (within 6 hours or between 6 and 12 hours) had a higher mortality rate than those who were operated on late (12 to 48 hours after injury). However, patients who were operated on early presented with poor clinical conditions, rendering worse outcomes (7).

\section{Clinical Category}

Clinical studies were the most common in our review, and they were initially focused on sporadic cases of spontaneous spinal EDH. Subsequently, posterior fossa and spinal EDHs were studied in a larger number of patients, with a focus on management outcomes and prognostications. The second top-cited paper in the clinical category (ranked $14^{\text {th }}$ overall, spinal EDH article) is "The syndrome of spontaneous spinal epidural hematoma. Report of three cases" by Markham et al., published in the Journal of Neurosurgery in 1976. It received 120 CC and 2.26 CY. The authors described three cases of spontaneous spinal EDH and reviewed an additional 46 cases from the literature. They concluded that spontaneous spinal $\mathrm{EDH}$ is a distinct clinical entity that needs to be considered in patients presenting with symptoms of spinal cord compression (24). The third top-cited article in the clinical category (ranked $17^{\text {th }}$ overall, spinal EDH article), with $111 \mathrm{CC}$ and $4.11 \mathrm{CY}$, is Gundry and Heithoff's "Epidural hematoma of the lumbar spine: 18 Surgically confirmed cases," published in Radiology in 1993. In this paper, 18 cases of surgically treated lumbar spine EDH were reported. Concomitant disk abnormalities were observed in $78 \%$ of the patients. It was postulated that a displaced disk may lead to the tearing of adjacent veins, resulting in $\mathrm{EDH}$ formation (12).

\section{Etiology Category}

Etiology was the second most studied category. Earlier studies were focused on epidural anesthesia and coagulopathies as causes of spinal EDHs and then shifted to emphasizing thrombolysis and anticoagulants as risk factors for spinal EDHs. After 2000, the risk factors of traumatic spinal EDH and, more recently, the risk of $\mathrm{EDH}$ following lumbar spine surgery were studied. The second most cited article in this category (ranked $7^{\text {th }}$ overall, spinal EDH article), with 207 CC and 6.9 CY, is "Spontaneous spinal epidural hematoma with associated platelet dysfunction from excessive garlic ingestion: A case report" by Rose et al., published in Neurosurgery in 1990. In this paper, the authors interestingly proposed that excessive garlic ingestion can result in platelet dysfunction and, therefore, contribute to the pathogenesis of spontaneous spinal EDH (30).

\section{Management Category}

Articles centered on the management of EDH were popular after the 1990s. Earlier studies on spinal EDHs were focused on conservative options, while later studies discussed the role of decompressive surgery and the optimal timing for decompression. For cranial EDHs, earlier articles discussed both operative and non-operative options. In 2006, Bullock et al. (5) defined the surgical indications for EDH. A noteworthy article on the management of EDH is Groen's "Non-operative 
treatment of spontaneous spinal epidural hematomas: A review of the literature and a comparison with operative cases" (ranked $12^{\text {th }}$ overall) published in Acta Neurochirurgica in 2004. It received 145 CC and 9.06 CY. This article compared cases of conservatively treated spontaneous spinal EDH with those surgically treated. The authors concluded that surgical decompression and hematoma evacuation should be the mainstays of treatment, and the decision to pursue conservative treatment has to be weighed based on the severity of the neurological deficits (10).

\section{Diagnosis category}

In the diagnosis category, most of the papers were published in the 1990s, with the initial studies focusing on cranial EDH, specifically on CT scans, and then shifting to MRI findings of both cranial and spinal EDH. The most-cited paper in this category ( $^{\text {th }}$ highest overall under the category of spinal $E D H)$ is "Spontaneous spinal epidural hematoma: Findings at MR imaging and clinical correlation," published by Holtås et al. in Radiology in 1996. It received $228 \mathrm{CC}$ and $9.5 \mathrm{CY}$. The authors reviewed the radiological images of 13 patients, demonstrating the hematoma location in the anterior epidural space in 8 patients, the posterior epidural space in 4 patients, and both anterior and posterior epidural spaces in one patient. Additionally, the earliest descriptions of signal changes were described by Holtås et al. based on signal changes on T1weighted $\mathrm{MRI}$, which went from isointense in the early period to hyperintense in the intermediate period (14).

\section{Prognosis category}

The trend of publication in the prognosis category started with case reports describing predictors of good recovery in spontaneous spinal EDH. Subsequently, retrospective studies were produced addressing the functional outcomes of spinal $\mathrm{EDH}$, the impact of time on surgical outcomes of spontaneous spinal $\mathrm{EDH}$, and the prognostic impact of anisocoria on the clinical outcome of cranial EDH. One of the most-cited articles in this category is Foo and Rossier's "Preoperative neurological status in predicting the surgical outcome of spinal epidural hematomas," which received 220 CC and 5.64 CY (ranked 5th overall, spinal EDH article). It was published in Surgical Neurology in 1981. In this paper, the authors discussed the predictors and outcomes of patients with spontaneous spinal EDH treated surgically. Return to normal function was noted in $95.3 \%$ of the patients presenting with incomplete sensorimotor lesions, $87 \%$ of those with incomplete sensory but complete motor lesions, and $45.3 \%$ of those with complete sensorimotor lesions. Foo and Rossier concluded that postoperative recovery is mainly dependent on the preoperative neurological status. Nonetheless, the absence of sensory or motor function pre-operatively does not necessarily lead to poor prognosis (8).

\section{Epidemiology category}

Epidemiological studies contributed to five articles on our list, all published between 2006 and 2013. All five focused mainly on addressing the incidence and risk factors of postoperative spinal EDH and the risk of spinal EDH following epidural anesthesia. The most-cited paper in this category, which ranked 6th on our list, is "Incidence of epidural hematoma, infection, and neurologic injury in obstetric patients with epidural analgesia/anesthesia" by Ruppen et al. It was published in Anesthesiology in 2006, and received 213 CC and $15.21 \mathrm{CY}$. It also consists of the highest evidence level in the list. This meta-analysis estimated the risk of spinal EDH following epidural anesthesia in obstetrics practice to be 1-11 per million (31).

\section{Pathophysiology category}

One article was published in the pathophysiology category, and it was ranked 8th overall among the spinal EDH articles. Beatty and Winston's "Spontaneous cervical epidural hematoma. A consideration of etiology," published in the Journal of Neurosurgery in 1984, has 205 CC and 5.75 CY. In this paper, the authors proposed that the source of bleeding in cases of cervical EDH is mainly arterial and that this observation can be extrapolated to spontaneous EDH at other spinal levels (4). Publications prior to this article speculated on the venous origin of $\mathrm{EDH}$; this article marked the shift to pathophysiological thinking of $\mathrm{EDH}$, due to which it received a high number of citations.

\section{Limitations}

Bibliometric studies have their limitations and usability in the literature. The following are the inherited limitations to bibliometrics: There is an overrepresentation of old studies compared to recent ones, which can be minimized by using the citation count per year, but this still does not lead to the identification of recent highly impactful publications. Selfcitation among authors acts as an over-quantification bias, but this was minimal in our bibliometric review on EDH. The understanding that highly cited works are highly impactful is not completely accurate; many impactful or field-changing studies often do not get included in bibliometric studies. EDHspecific limitations exist in our search; "extradural hematoma" was not used as a search keyword in our study, due to which some highly cited articles were omitted even though they were relevant. The Scopus database covers the full citation profiling of articles between 1970 and 2020, and the articles' citations before 1970 might have been underrepresented.

\section{CONCLUSION}

The literature on EDH started with case reports describing various etiologies and risk factors, specifically for spinal $\mathrm{EDH}$. Subsequently, diagnostic studies were popular, and they mainly addressed the utility of MRI in the diagnosis of spinal EDH. Later, more papers were produced on the surgical indications, management options, timing of surgery, and outcomes of EDHs. This paper can serve as a valuable tool to guide clinicians and scientists in evidence-based practice as it reflects the publication trends and research interests related to $\mathrm{EDH}$. 


\section{REFERENCES}

1. Alfaifi A, AlMutairi OT, Allhaidan M, Alsaleh S, Ajlan A: The top 50 most-cited articles on acoustic neuroma. World Neurosurgery 111:e454-e464, 2018

2. Almutairi O, Albakr A, Al-Habib A, Ajlan A: The top-100 mostcited articles on meningioma. World Neurosurgery 107:10251032, 2017

3. Alotaibi NM, Nassiri F, Badhiwala JH, Witiw CD, Ibrahim GM, Macdonald RL, Lozano AM: The most cited works in aneurysmal subarachnoid hemorrhage: A bibliometric analysis of the 100 most cited articles. World Neurosurgery 89:587-592, 2016

4. Beatty RM, Winston KR: Spontaneous cervical epidural hematoma: A consideration of etiology. J Neurosurg 61(1): 143-148, 1984

5. Bullock, M. R., Chesnut, R., Ghajar, J., Gordon, D., Hartl, R., Newell, D. W., ... \& Wilberger, J. E.: Surgical management of acute epidural hematomas. Neurosurgery, 58, S7-15, 2006 Discussion Siiv.

6. Cordobés F, Lobato RD, Rivas JJ, Muñoz MJ, Chillón D, Portillo JM, Lamas E: Observations on 82 patients with extradural hematoma: Comparison of results before and after the advent of computerized tomography. J Neurosurg 54(2): 179-186, 1981

7. Fernández-Abinader JA, González-Colón K, Feliciano CE, Mosquera-Soler AM: Traumatic brain injury profile of an elderly population in Puerto Rico. P R Health Sci J 36(4):237239, 2017

8. Foo D, Rossier AB: Preoperative neurological status in predicting surgical outcome of spinal epidural hematomas. Surg Neurol 15(5):389-401, 1981

9. Freytag E: Autopsy findings in head injuries from firearms. Statistical evaluation of 254 cases. Arch Pathol 76:215-225, 1963

10. Groen RJM: Non-operative treatment of spontaneous spinal epidural hematomas: a review of the literature and a comparison with operative cases. Acta Neurochir 146(2):103110, 2004

11. Groen RJ, Ponssen H: The spontaneous spinal epidural hematoma: A study of the etiology. J Neurol Sci 98(2-3):121138,1990

12. Gundry CR, Heithoff KB: Epidural hematoma of the lumbar spine: 18 surgically confirmed cases. Radiology 187(2):427431, 1993

13. Heiskanen O: Epidural hematoma. Surgical Neurology 4(1): 23-26, 1975

14. Holtås S, Heiling M, Lönntoft M: Spontaneous spinal epidural hematoma: Findings at MR imaging and clinical correlation. Radiology 199(2):409-413, 1996

15. Ibrahim GM, Carter Snead III O, Rutka JT, Lozano AM: The most cited works in epilepsy: Trends in the "Citation Classics". Epilepsia 53(5):765-770, 2012
16. Jeong YH, Oh JW, Cho S, Korean Trauma Data Bank System Committee: Clinical outcome of acute epidural hematoma in Korea: Preliminary report of 285 cases registered in the Korean trauma data bank system. Korean J Neurotrauma 12(2):47-54, 2016

17. Kim HJ, Yoon DY, Kim ES, Lee K, Bae JS, Lee JH: The 100 most-cited articles in neuroimaging: A bibliometric analysis. Neuroimage 139:149-156, 2016

18. Lapadula G, Federico C, Paolini S, Missori P, Domenicucci, M: Epidural hematoma with detachment of the dural sinuses. J Neurosci Rural Pract 5(2):191-194, 2014

19. Lawton MT, Porter RW, Heiserman JE, Jacobowitz $R$ Sonntag VK, Dickman CA: Surgical management of spinal epidural hematoma: Relationship between surgical timing and neurological outcome. J Neurosurg 83(1):1-7, 1995

20. Lefaivre KA, Shadgan B, O'Brien PJ: 100 most cited articles in orthopaedic surgery. Clin Orthop Relat Res 469(5):1487-1497, 2011

21. Li L, Ma X, Pandey S, Deng X, Chen S, Cui D, Gao L: The mostcited works in severe traumatic brain injury: A bibliometric analysis of the 100 most-cited articles. World Neurosurg 113:e82-e87, 2018

22. Lobato RD, Rivas JJ, Cordobes F, Alted E, Perez C, Sarabia R, Cabrera A Cabrera, Diez I, Gomez P, Diez I, Gomez P, Lamas E: Acute epidural hematoma: An analysis of factors influencing the outcome of patients undergoing surgery in coma. J Neurosurg 68(1):48-57, 1981

23. Mariam N, Cavanna AE: The most cited works in Tourette syndrome. J Child Neurol 27(10):1250-1259, 2012

24. Markham JW, Lynge HN, Stahlman GE: The syndrome of spontaneous spinal epidural hematoma: Report of three cases. J Neurosurg 26(3):334-342, 1967

25. Mazhari S: The 100 top-cited articles published in psychiatric journals. J Psychiatr Pract 19(4):327-338, 2013

26. Moed HF: New developments in the use of citation analysis in research evaluation. Arch Immunol Ther Exp 57(1):13-18, 2009

27. Murray MR, Wang T, Schroeder GD, Hsu WK: The 100 most cited spine articles. Eur Spine J 21(10):2059-2069, 2012

28. Nason GJ, Tareen F, Mortell A: The top 100 cited articles in urology: An update. Can Urol Assoc J 7(1-2):E16, 2013

29. Ponce FA, Lozano AM: The most cited works in Parkinson's disease. Mov Disord 26(3):380-390, 2011

30. Rose KD, Croissant PD, Parliament CF, Levin MB: Spontaneous spinal epidural hematoma with associated platelet dysfunction from excessive garlic ingestion: A case report. Neurosurgery 26(5):880-882, 1990

31. Ruppen W, Derry S, McQuay H, Moore RA: Incidence of epidural hematoma, infection, and neurologic injury in obstetric patients with epidural analgesia/anesthesia. Anesthesiology 105(2):394-399, 2006

32. Soon WC, Marcus H, Wilson M: Traumatic acute extradural haematoma-Indications for surgery revisited. $\mathrm{Br} \mathrm{J}$ Neurosurg 30(2):233-234, 2016 